\title{
Eczacılık Ürünleri İhracat Performanslarının Belirlenen Endekslerle Ölçülmesi: Türkiye - Brezilya Örneği \\ (Measurement of Export Performance of Pharmaceutical Products With Determined Indices: Turkey- Brazil Example)
}

\section{Zübeyir TURAN ${ }^{(D)}$ a Sabri Can KAYIKÇIOĞLU $\left({ }^{D}{ }^{b}\right.$ Ahmet Enes ÇAĞLAR ${ }^{(D)}$ c \\ a Niğde Ömer Halisdemir Üniversitesi, İktisadi ve İdari Bilimler Fakültesi, İktisat Bölümü, Niğde, Türkiye. z turan63@hotmail.com \\ b Niğde Ömer Halisdemir Üniversitesi, Sosyal Bilimler Enstitüsü, İktisat Bölümü, Niğde, Türkiye. kayikcioglusabrican@gmail.com \\ c Niğde Ömer Halisdemir Üniversitesi, Sosyal Bilimler Enstitüsü, İktisat Bölümü, Niğde, Türkiye. ahmetenescaglar@gmail.com}

\begin{tabular}{|c|c|}
\hline MAKALE BİLGİSİ & ÖZET \\
\hline $\begin{array}{l}\text { Anahtar Kelimeler: } \\
\text { Eczacilik }\end{array}$ & $\begin{array}{l}\text { Amaç - Bu çalışmanın amacı, Türkiye ve Brezilya'da eczacılık ürünleri ihracat performanslarının } \\
\text { belirlenen endekslerle ölçülerek sonuçların karşılaştııılmasıdır. }\end{array}$ \\
\hline $\begin{array}{l}\text { Rekabet } \\
\text { İhracat } \\
\text { Türkiye } \\
\text { Brezilya. }\end{array}$ & $\begin{array}{l}\text { Yöntem - Rekabet gücünün ölçümünde 2008-2017 yılları arasında iki ülkenin ve dünyada yapılan } \\
\text { eczacılık sektöründeki ihracat oranları kullanılarak Açıklanmış Karşılıklı Üstünlükleri Endeksi, } \\
\text { Nispi İhracat Avantajı Endeksi ve Karşış̧ırmalı İhracat Performans Endeksleri ölçülmüştür. } \\
\text { Bulgular - Eczacılık sektörünün yüksek maliyetli yapısının olması, uzmanlaşmış iş gücünün } \\
\text { istihdam edilmesi, teknolojik alt yapının önemli olması, Ar-Ge faaliyetlerinin uzun zaman alması }\end{array}$ \\
\hline Gönderilme Tarihi 18 Temmuz & ve kişi sağlığını ilgilendirmesi sektörü yüksek öneme sahip olduğunu göstermektedir. \\
\hline $\begin{array}{l}2019 \\
\text { Revizyon Tarihi } 13 \text { Kasım } 2019 \\
\text { Kabul Tarihi } 18 \text { Kasım } 2019\end{array}$ & $\begin{array}{l}\text { Tartışma - Avrupa ülkeleri içinde bulunan Türkiye ve Latin Amerika ülkesi olan Brezilya'nın } \\
\text { eczacılık sektöründe rekabet güçlerinin ölçülerek karşılaştırmalı üstünlüklerinin } \\
\text { avantaj/dezavantaj durumları belirlenmeye çalışılmışır. Elde edilen sonuçlarda iki ülkenin de } \\
\text { rekabet gücünün dezavantajlı olduğu belirlenmiş ve Brezilya'nı Türkiye ye nispeten } \\
\text { karşılaştırmalı üstünlüklerde avantajlı olduğu sonucuna varılmıştır. }\end{array}$ \\
\hline ARTICLE INFO & ABSTRACT \\
\hline $\begin{array}{l}\text { Keywords: } \\
\text { Pharmacy }\end{array}$ & $\begin{array}{l}\text { Purpose - The pupose of this study is to measure export performances of Turkey and Brazil via the } \\
\text { designated indexes of pharmaceutical products and compare the obtained results. }\end{array}$ \\
\hline $\begin{array}{l}\text { Competition } \\
\text { Export } \\
\text { Turkey }\end{array}$ & $\begin{array}{l}\text { Design/methodology/approach - The Comparative Export Advantage Index and the Comparative } \\
\text { Export Performance Indices were measured between } 2008 \text { and } 2017 \text { using the export rates of the } \\
\text { two countries and the pharmaceutical sector in the world. }\end{array}$ \\
\hline Received 18 July 2019 & $\begin{array}{l}\text { Findings - The high cost structure of the pharmaceutical industry, private labor employment, } \\
\text { technological infrastructure is important, R\&D activities take a long time and show that concern } \\
\text { for human health is of high importance of the industry. }\end{array}$ \\
\hline $\begin{array}{l}\text { Revised } 13 \text { November } 2019 \\
\text { Accepted } 18 \text { November } 2019\end{array}$ & $\begin{array}{l}\text { Discussion - In the pharmaceutical sector of Turkey and Brazil, which is the country of Latin } \\
\text { America in European countries, comparative advantages/disadvantages of the competitive } \\
\text { strengths were measured and tried to determine the situation. As a result, it was determined that } \\
\text { the competitiveness of the two countries is disadvantageous and Brazil has advantages to Turkey. }\end{array}$ \\
\hline
\end{tabular}

\section{GİRIŞ}

Ekonomik ve politik anlamda ülkelerin uluslararası piyasalara hâkim olması ve piyasaya yön verecek kararlarda karar verici olmak için dış ticaret hacminin öneminin bilinmesi gerekmektedir. Dış ticaretin getirileri ülkeler için oldukça fazladır çünkü dış ticareti fazla olan bir ülke de ekonominin büyümesi söz konusudur. Bu büyüme ile birlikte refah artışı gelecektir daha sonra istihdam artacaktır ve ülkenin gelişmiş ülkeler seviyesinde ekonomik yapıya sahip olacaktır. Makro açıdan bakıldığında bu sayılan gelişimlerin olması için mikroekonomideki işletme ve endüstrilerin gelişme göstermesi gerekmektedir (Erkan, 2012: 195). İşletme ve firmaların günümüzde artan rekabet için pazar paylarını kaybetmemek ve pazar paylarını

\section{Önerilen Atıf/Suggested Citation}

Turhan, Z., Kayıkçığlu, S. C., Çağlar, A. E. (2019). Eczacılık Ürünleri İhracat Performanslarının Belirlenen Endekslerle Ölçülmesi: Türkiye - Brezilya Örneği, İşletme Araştırmaları Dergisi, 11 (4), 2680-2690. 


\section{Z. Turhan - S. C. Kayıkçığlu - A. E. Çağlar 11/4 (2019) 2680-2690}

artırmak için rekabet gücünü artırmaları gerekmektedir. Rekabet gücünün artmasını isteyen işletme/endüstriler iş gücünde uzmanlaşmaya gitmektedirler. Uzmanlaşmanın artması sektörün gelişmesine ve pazar payının artmasına neden olacaktır.

Pazar paylarını artıran ülkeler sektördeki rakiplerinin önüne geçerek pazara hâkim olmak veya hâkim oldukları pazarları kaptırmak için ihracatını artırarak karşılaştırmalı üstünlüğe ve ihracat üstünlüğünü ellerinde tutmaları gerekmektedir. Karşılaştırmalı üstünlüklerin ve ihracat üstünlügünün önemi ise ülkenin belirlenen sektörde toplam ihracatının, dünyada o sektör içindeki ihracat payının içinde yüksek olması rekabet gücünün yükselmesinde önemli bir noktadır. Bu açıdan ülkelerin sektör ve mal bazında ihracatının ölçülmesinde açıklanmış karşılaştırmalı üstünlükler, nispi ihracat avantajı ve karşılaştırmalı ihracat avantajları endeksleri oldukça önemlidir.

Rekabetin yaşandığı birçok sektör bulunmaktadır. Bu sektörlerden biri olan eczacıllk sektöründe de yukarıda anlatılan durumlar geçerlidir. Eczacılık kelime anlamıyla ilaç üreten satan anlamına gelmektedir. Üretim ve satımının olduğu piyasalar da rekabet söz konusudur. Bu sektörde rekabetin oluşması için birçok faktörün elde edilmesi gerekmektedir. Özellikle eğitimli uzmanlaşma, Ar-Ge faaliyetleri, teknolojik alt yapı ve talebin olması gerekmektedir. Bu faktörlerin devlet destekli veya çok uluslu firmalar tarafından oluşturulmasıyla sektörde rekabet gücü elde edilebilir. Özellikle eczacıllk sektöründe ve sağlık sektörünü de rekabet gücünün artması oldukça önemlidir.

$\mathrm{Bu}$ çalışmanın amacı ise Eczacılık ürünleri ihracat performanslarının belirlenen endekslerle ölçülerek sonuçların karşılaştııılmasıdır. Karşılaştırmada kullanılacak ülkeler ise Türkiye ve Brezilya olacaktır. İki ülkenin de konumları incelendiğinde farklı kıtaları kapsadıkları ve eczacılık sektörü ihracat oranları birbirine yakın oldukları için bu iki ülke belirlenmiştir. Bu iki ülkenin 2008-2017 yılları arasında yapılan eczacılık ihracat verileri kullanılarak elde edilen karşılaştırmalı üstünlükleri ve ihracat üstünlüklerinin avantajlı/dezavantaj durumları değerlendirilmiştir.

Bu çalışma dört bölümden oluşmaktadır. İlk bölümde uluslararası rekabet gücü hakkında bilgi verilmiştir. İkinci bölümde ise Türkiye ve Brezilya eczacılık sektörü tanıtılmıştır. Üçüncü bölümde ise araştırmada kullanılacak metodoloji ve veri seti verilmiştir. Dördüncü ve son bölümde ise ampirik bulgular üzerine bir değerlendirme yapılmıştır.

\section{ULUSLARARASI REKABET GÜCÜ: TANIM VE KAPSAMI}

Yapılan literatür çalışmalarında Ulusal Rekabet Gücünün genel anlamda iki farklı bakış açısıyla incelendiği görülmektedir. Bunlar mikro ekonomik bakış açısı ve makroekonomik bakış açısıdır. Mikroekonomik bakış açısına göre firma ve endüstrilerin rekabet etme, büyüme ve performansları ölçülmektedir. Ölçümlerin olumlu sonuçlanması için istikrarlı, verimli ve kârlı üretim yapılarak büyük bir Pazar payına sahip olması gerekmektedir. Makroekonomik bakış açısı ise temelinde ülke içindeki firma ve endüstrilerin uzmanlaştıkları alanlarda farklı ve verimli mal ve hizmet üretimleri sayesinde ülke içinde istihdamın, refah artışının ve diğer olanakların sağlanmasıyla ülkenin diğer ülkelerle rekabet etmesini sağlamaktadır (Kumral, 2008: 3).

Rekabet gücü temelinde incelendiği zaman endüstrinin/sektörün ülke içindeki ve ülke dışındaki aynı sektörlerle birlikte yüksek gelir elde etme, yüksek istihdam düzeyi sağlama ve verimli üretim yapabilme gücü tanımlanabilir. Bu nedenle uluslararası rekabetin içinde olan bir ülkenin bir başka ülkeyle kıyaslanmasında incelenen fiyat, kalite ve tasarım gibi bazı noktalarda yarışabilecek seviyede olması gerekmektedir. Ülkeler için rekabet gücü büyük oranda firmaların verimliliği ve üretkenliğinden geçse de rekabet gücünün süreklilik arz etmesi ve dışarı çevre ile etkileşim içinde teknoloji ve yeniliklere açık olması gerekir (Koç ve Ozbozkurt, 2014: 86).

Uluslararası pazarda kendine yer etmiş bir ülkenin temel amacı ülke vatandaşlarının net gelirlerini artırmak ve istihdam oranını yükselterek refah artışını sağlamak istemesidir. Refah artışını sağlayabilmesi için üretilen mal ve hizmetlerin uluslararası platformda sunulup pazarlanabilmesi gerekmektedir. Pazar piyasasına sürülen bir ürünün tutunabilmesi için Ar-Ge faaliyetleriyle geliştirilmiş, ileri teknoloji kullanarak verimli ürün üretilmesinden geçmektedir. Üretilen ürün makro açıdan ülkenin dünyadaki konumunu belirlemekte etkili olacak ve rakip ülkelere karşılaştırmalı üstünlük sağlayacaktır (Çivi vd., 2008: 3). 
İktisadi açıdan incelendiğinde rekabet gücü girişimcilik ve teori açısından farklılıkların olduğu görülmektedir. Rekabet gücü teori olarak ele alındığında içerik ve farklı bakış açılarıyla inceledikleri görülmektedir. Yapılan incelemelerde iktisatçların büyük bir bölümü makro ve mikro bakış açısındaki rekabet gücünün eksikliklerine vurgu yaparak yeni bir bakış açısı getirmişlerdir. İktisadi açıdan yapılan rekabet gücü bakış açısı göreceli üstünlüklere vurgu yapma, rekabet gücü olgusunu arz-talep mekanizmasında incelemek ve rekabet üstünlüğünü ölçek ekonomisiyle entegrasyonunu üzerinde çalışmışlardır (Gökmenoğlu vd., 2012: 6). Uluslararası rekabet gücü incelendiğinde ortaya atılan teorilerin gerçekte uluslararası pazarda ülkelerin konumunu belirlemeye yönelik açıklamalar olduğu görülmektedir. Başka bir söylemle de uluslararası ticarette rekabet gücünü belirlemek, rekabet gücünü artırmak ve söz edilen açılamalara 1şık tutmaktır (Timurçin, 2010: 57).

Uluslararası rekabet gücü ölçümlerinde çalışmalar yürüten iktisatçılar ve görüşleri literatür çalışması olarak incelenmiştir.

Tablo 1: İktisat Teorilerine Göre Rekabet Gücü

\begin{tabular}{|c|c|}
\hline İKTİSATÇILAR VE TEORILERİ & REKABET GÜCÜ GÖRÜŞLERİ \\
\hline $\begin{array}{c}\text { ADAM SMITH (1766) } \\
\text { MUTLAK ÜSTÜNLÜKLER TEORİSİ }\end{array}$ & $\begin{array}{l}\text { Kaynakların verimli kullanarak dış ticarette elde } \\
\text { edilen kârın mutlak maliyet avantajını sağlaması } \\
\text { gerektiğini vurgulamıştır. }\end{array}$ \\
\hline DAVID RICARDO (1877) & $\begin{array}{l}\text { A. Smith gibi kaynakların verimli kullanılmasından } \\
\text { bahseder yalnız kârlılığı mutlak maliyet avantajına } \\
\text { göre değil göreceli maliyet avantajını sağlaması } \\
\text { gerektiğini vurgular. }\end{array}$ \\
\hline FAKTÖR DONATIMI TEORISİ & $\begin{array}{l}\text { Bir ulusun karşılaştırmalı üstünlüğün temelinde } \\
\text { faktör donatımı teorisi olduğunu söylemişlerdir. Yani } \\
\text { emek-yoğun ülke ile emek-yoğun ülke sermaye- } \\
\text { yoğun ülke ile sermaye-yoğun ülke aralarında ihracat } \\
\text { yapması gerektiğini rekabet gücü faktör fiyatlarına } \\
\text { dayandırır. }\end{array}$ \\
\hline LEONTIEF PARADOKSU & $\begin{array}{l}\text { H-Ohlin faktör donatımı teorisi ulusların rekabet } \\
\text { gücünü açıklamakta yetersiz bulunaktaydı. Çünkü } \\
\text { varsayımların içinde olan girdilerin aynı nitelikte } \\
\text { olması, nitelikli, eğitimli ve teknolojik iş gücü ile } \\
\text { niteliksiz eğitimsiz düşük teknolojiyi bir tutmaktaydı. } \\
\text { Leontief teorisi üzerine ilk çalışmasını yaparak } \\
\text { sermayesi çok emek kaynağı kıt olan ABD'nin emek- } \\
\text { yoğun mallar ihraç edip sermaye-yoğun malları ithal } \\
\text { ettiğini bulmuştur. Bunun nedeni olarak da ABD } \\
\text { işçisinin eğitimli nitelikli olmasından kaynaklandığını } \\
\text { söylemiştir. }\end{array}$ \\
\hline NEO - FAKTÖR DONATIMI TEORİII & $\begin{array}{l}\text { Emek faktörünün homojen benimsenmemesi } \\
\text { gerektiğini söylemişler ve nitelikli iş gücü teorisini } \\
\text { benimsemişlerdir. Ülkeler nitelikli iş gücüne sahip } \\
\text { olduğu faktörlerde uzmanlaşması gerektiğini } \\
\text { niteliksiz iş gücüne sahip olan ülkelerde diğer } \\
\text { faktörlerde uzmanlaşması gerektiğini savunmuştur. }\end{array}$ \\
\hline
\end{tabular}




\begin{tabular}{|c|c|}
\hline & Bu durumun refah artışına neden olacağını savunur. \\
\hline $\begin{array}{c}\text { POSNER (1961) } \\
\text { TEKNOLOJİ AÇIĞI TEORİsi }\end{array}$ & $\begin{array}{l}\text { Günümüzde uluslararası rekabet gücünü } \\
\text { unsurlarından olan eğitimli iş gücünün sıklıkla } \\
\text { yararlandığı alanlardan biri olan Ar-Ge faaliyetlerinin } \\
\text { kullanılmasının temelini oluşturmuştur. Posner ‘a } \\
\text { göre teknolojik yenilikler yapan ülkeler ticarette } \\
\text { karşılaştırmalı üstünlük elde edeceğini savunmuş ve } \\
\text { bunu da teknoloji yenilik teorisinde açılamıştır. }\end{array}$ \\
\hline ÜRÜN DÖNEMLERİ TEORİSİ & $\begin{array}{l}\text { Teknoloji ve nitelikli iş gücünün sağlanmasıyla } \\
\text { birlikte yeni ürünleri üreten ülkeleri ihraç ettikleri } \\
\text { niteliksiz işgücünün olduğu ülkelerde daha ucuza } \\
\text { üretip karşılaştırmalı üstünlükte öne geçebileceğini } \\
\text { vurgulamıştır. Bu teoride ürün dönemleri teorisi } \\
\text { olarak ileri sürmüştür. Daha sonraki yıllarda } \\
\text { Krugman, Grossman, Helpman ve Lai tarafından } \\
\text { ilerlemesine katkı sağlanmıştır. }\end{array}$ \\
\hline ÖRTÜŞEN TALEPLER TEORİSİ & $\begin{array}{l}\text { Ülkeler arası gelir seviyesinin aynı olan ülkeler } \\
\text { arasında ticaretin daha fazla olacağını vurgular. Arz } \\
\text { yönlü dış ticaret modelinin aksine talep yönlü bir } \\
\text { teori olan örtüşen talepler teorisini ortaya koyar. } \\
\text { Balassa, Grubel ve Kravis tarafından eleştirilmiştir. } \\
\text { Krugman tarafından ise geliştirilerek ölçek } \\
\text { ekonomiler, endüstri içi ticaret ve ürün } \\
\text { farklılaştırılması teorilerinin temelinde dayandığı } \\
\text { nokta Linder'in örtüşen talep teorisine } \\
\text { dayanmaktadır. }\end{array}$ \\
\hline DIŞSAL ÖLÇEK TEORİSİ & $\begin{array}{l}\text { Endüstride aynı konumda olan firmaların } \\
\text { oluşturacağı kümeleşme sayesinde firmaların bilgi } \\
\text { aktarımında, teknolojik yayılımlarında, Ar-Ge ve } \\
\text { uzman iş gücü birlikteliği ile endüstrinin gelişmesine } \\
\text { ve entegre olmasıyla rekabet gücünün artacağını } \\
\text { dışsal ölçek teorisiyle ileri sürmüştür. }\end{array}$ \\
\hline
\end{tabular}

Kaynak: Yazar Tarafından Oluşturulmuştur.

Yukarıda yapılan tanım ve açıklamalardan uluslararası rekabet gücünün özelliklerini şu şekilde sıralanabilir;

- Rekabet gücünü elde etmek isteyen bir ülke, ülke içi endüstri/sektör yapılarında üretilen mal ve hizmetlerle ülke vatandaşının gelir düzeyinin artmasına, istihdam oranının yükselmesine, nitelikli iş gücünün oluşturulmasına ve refah artışının sağlanmasıyla uluslararası pazarda nitelikli ürünler sunmasiyla mümkündür.

- Mal ve hizmetlerin dağıtılmasında rekabet edilen ülkeleri önüne geçebilmesinde ülkenin konumunu, üretim potansiyelini dikkate alması gerekmektedir.

- Endüstri/sektör içindeki firmaların Ar-Ge faaliyetleri ve teknolojik gelişmeleri yakından takip etmeli, uzman iş gücü ile verimli mal ve hizmetler üretmelidir. 


\section{Z. Turhan - S. C. Kayıkçığlu - A. E. Çağlar 11/4 (2019) 2680-2690}

- Ülkelerin ulusal pazara sunulan mal ve hizmetlerin iyi bir şekilde pazarlanması yapılarak pazar piyasandaki konumunu koruyup rekabet gücünü artırabilmelidir.

\section{TÜRKIYYE VE BREZILYA ECZACILIK SEKTÖRÜ}

Trade Map'den alınan verilere göre eczacılık sektöründe dünya endüstrisinde en çok ihracat payına sahip olan ülkeler Çin $(\% 12,9)$, Amerika Birleşik Devletleri $(\% 8,8)$, Almanya (\%8,3), Japonya (\%4), Kore Cumhuriyeti $(\% 3,3)$ gelmektedir. Araştırmamızın konusunu oluşturan Türkiye'nin eczacılık sektöründe dünya ihracat payı \%0,9'luk oranla 31.sırada yer alırken, Brezilya ise eczacılık sektöründeki dünya ihracat payı $\% 1,2^{\prime}$ lik bir oranla 25 . sirada yer almaktadır.

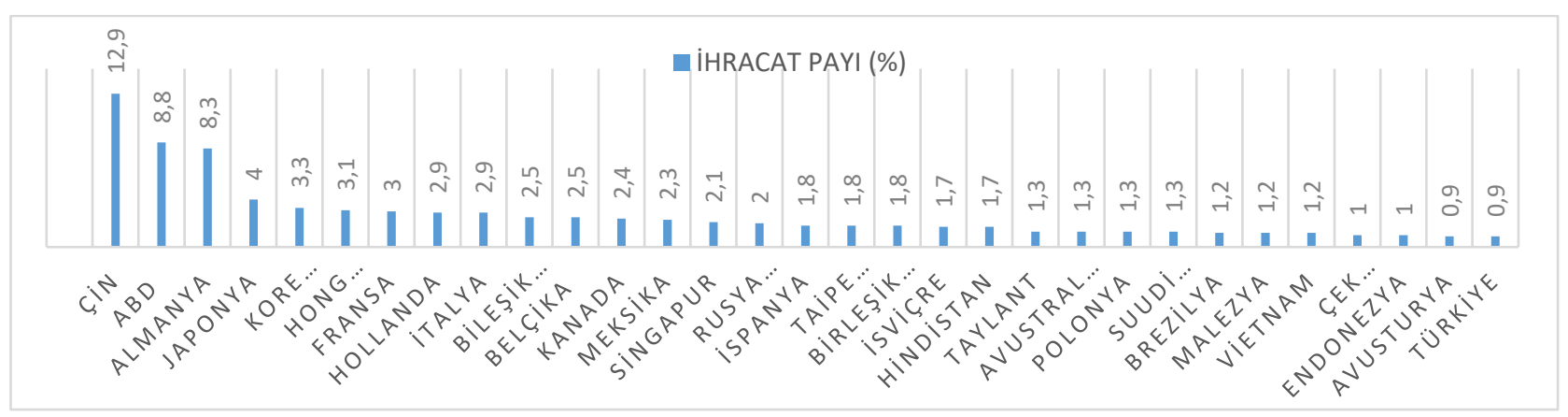

Şekil 1: Eczacılık Sektöründe 2017 Yılı Dünya İhracat Oranındaki Payı (\%) Kaynak:

\section{https://www.trademap.org}

Küresel pazarda rekabet eden Türkiye, ilaç üretim ve satımında sektördeki şirketler için oldukça önemli bir piyasadır. Bunun sebebi ise Türkiye'nin Ar-Ge faaliyetlerinin artmış olması, yaşam sürelerinin artmasından dolayı artan yaşlı nüfus oranı ve sağlık hizmetlerinin artmış olmasıdır. İlaç sektörünün ve dolayısıyla eczacıllk sektörünün önem kazanacağı beklenmektedir (TOBB, 2012: 2).

Türkiye eczacılık sektöründe uluslararası standartların uygulandığı ve üretilecek ürünlerin teknolojik alt yapısı olan sektörlerin başında gelmektedir. Türkiye fazla üretimi olmayan ve imalatta maliyeti yüksek olan ilaçları ithal ederek sektörün yoğunluğunu alarak diğer ilaçlarda uzmanlaşma yoluna gider. Türkiye'de 17 tanesi çok uluslu firma (ÇUF) olan 77 tane ilaç üretim tesisi, 15 tane ÇUF olan 71 tane üretici firma, 6'si ÇUF olan 12 tane hammadde üretim tesisi ve $4^{\prime}$ ü ÇUF olan 10 tane hammadde üretimi yapan firma yapısına sahiptir. İlaç üretim ve satış sektöründe 30.000 kişi istihdam edilmekte ve yarısından fazlası eğitim düzeyi yüksektir (Kaynak, 2016: 51). Bu durum Türkiye için özel sektörlerin ağırlıklı olduğunu göstermektedir.

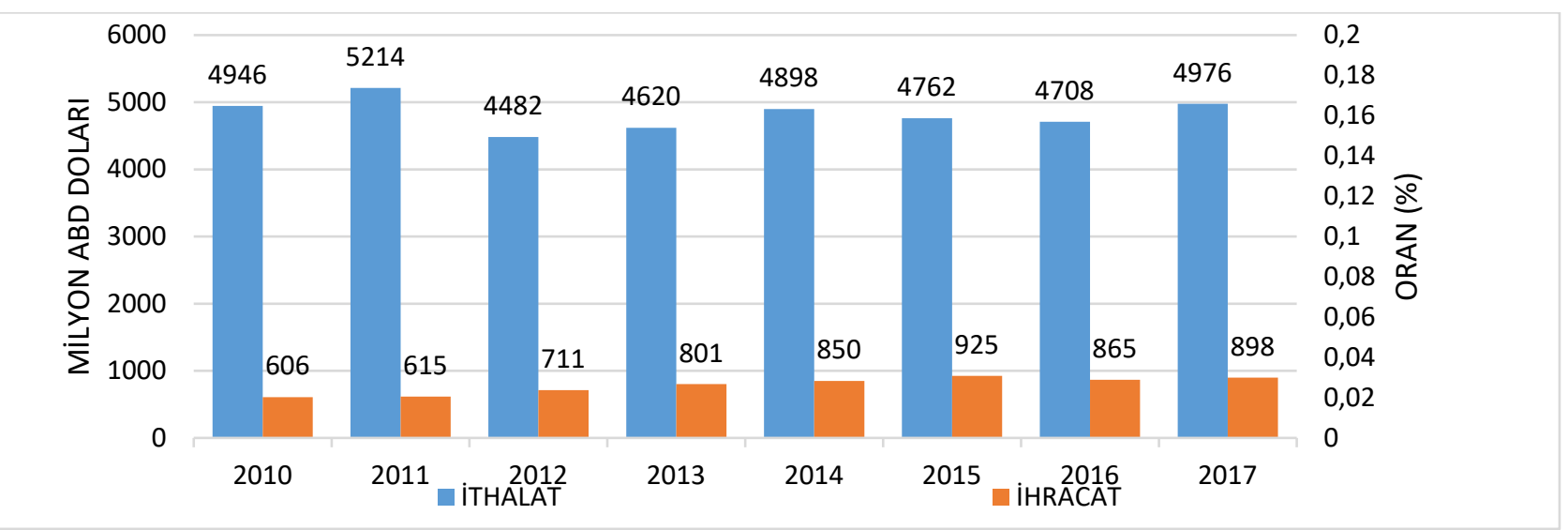

Şekil 2: Türkiye Eczacılık Sektörü İthalat-İhracat Oranları Kaynak: www.ieis.org.tr

Türkiye'nin eczacılık sektöründe dış ticaret hareketleri incelendiğinde yukarıdaki grafik de 2010 yılında 606 milyar dolarlık ihracatın gerçekleştiği görülmektedir. 2010 yılından 2016 yılına kadar olan sürede ise ihracat oranında 43,8 oranında artığ görülmektedir. 2016 yılında ABD dolarında yaşanan yükselişten etkilenen Türkiye 865 milyon dolarlık ihracat yaparak düşüşe geçmiştir. Fakat 2017 yılında dolarda yaşanan düşüler nedeni ile 2016 yılına kıyasla \%18,7 artarak 898 milyon dolar seviyesine yükseldi. Öte yandan ülkenin ithalat performansına bakıldığında 2014 yılında artan ithalat 2015-2016 yıllarında \%2,7 seviyelerine düşmüştür. 2017 yılında ihracatın artmasıyla ithalatında arttığı görülmektedir (IEİS, 2017: 21). Türk ilaç üretim yapısın 


\section{Z. Turhan - S. C. Kayıkçığlu - A. E. Çağlar 11/4 (2019) 2680-2690}

küresel standartlara uygun olarak faaliyet göstermesine rağmen istenen rekabet gücüne ulaşılamamıştır (Kaynak, 2016: 51).

Brezilya'nın eczacılık ve ilaç sektörü incelendiğinde çok sınırlı sayıda çalışma yapıldığı görülmektedir. Yapılan çalışma da ise Brezilyanın son yıllarda ilaç sektöründe büyük atılımlar yapmasın altında yatan en büyük sebebin yeni kalkınmacı devlet modelinin olmasıdır. Dünya ilaç piyasasındaki payı \%1,2 olan brezilya ilaç piyasasında 550 civarında firma yapısına sahiptir. Brezilya 2010 yılıyla birlikte ilk dört de bulunan firmaların piyasa koşullarında \%23'lük bir paya hâkimdir. Brezilya'daki eczacılık sektörünün önemli politikalarından biride kamusal ilaç laboratuvarların bulunmasıdır. Devlet desteği olan bu kamusal laboratuvarlarda ağırlıklı olarak jenerik ilaç alanında araştırmalar yapılmaktadır. Bunun nedeni 2792 jenerik ilacın $\% 89^{\prime}$ u ülke içinde üretilmekte olmasıdır. Brezilya dünya genelinde jenerik ilaç ihracatı ve teknoloji aktarmada özellikle de Afrika ülkeleri için önemli konumdadır. Brezilyanın gelecekte uluslararası ilaç sektöründe önemli bir yer alması beklenmektedir (Yaşgül, 2013: 141-146).

Yukarıdaki bilgilerinden de anlaşılacağı gibi Türkiye eczacılık sektöründe Brezilya ya kıyasla uluslararası rekabette daha geri bir seviyededir.

\section{YÖNTEM VE VERI SETİ}

Uluslararası rekabet gücü endeksi üzerinde yapılan çalışmalarda genellikle Amerika Birleşik Devletleri, Çin, Japonya gibi büyük ölçekli ekonomiye sahip olan ülkelerin sanayi Tekstil ve ülke içi rekabet edebilirliği temel alınarak araştırmalar yapılmıştır.

Birçok ülkede pek çok sektörde rekabet gücünün ölçülmesinde bazı endeksler kullanılmıştır. Bu endekslerden olan açıklanmış karşılaştırmalı üstünlükler endeksi, nispi avantaj endeksi ve karşılaştırmalı ihracat performansları endeksi bu çalışmada kullanılacak olan endekslerdir. Bu çalışmanın amacı belirlenen yıllarda ticaret sonrası verilerden oluşan göstergeler ile ülkeler arası rekabetin konumunu belirlemektir. Benzer amaç doğrultusunda ortaya konulmuş birçok amaç ve yöntem vardır. Bunlar Hillman (1980), Bowen (1938), Bollance (1985), Yeats (1985), Kojiman (1970), Kunimato (1977), Voltrath (1991)'dır. Bu yöntemler neticesinde her ülke için kullanılabilecek genel kabul görmüş bir model ortaya konulamamıştır (Aydoğmuş ve Diller, 2009: 8).

Bu çalışmada eczacılık sektöründe üretiminin Türkiye ve Türkiye'ye rakibi konumunda bulunan Brezilyanın 2008-2017 yılları arasındaki dış ticaretteki ihracat verilerinden yararlanılacaktır. Elde edilen veriler Trade Map'den alınmıştır.2018 yılına ait Türkiye, Brezilya ve dünyaya ait ihracat verileri TÜIK, Dünya Ticaret Örgütü ve Trade Map'de yayınlamadığı için çalışmada kullanılmamıştır.

Tablo 2. 2008-2017 Yılları Arasındaki Türkiye, Brezilya ve Dünyaya Ait İhracat Verileri $(\$ 1,000)$

\begin{tabular}{|c|c|c|c|c|c|c|}
\hline YILLAR & $\begin{array}{c}\text { Türkiye'nin } \\
\text { Eczacllı } \\
\text { Ürünleri } \\
\text { İhracatı }\end{array}$ & $\begin{array}{c}\text { Türkiye'nin } \\
\text { Toplam Mal } \\
\text { İhracatı }\end{array}$ & $\begin{array}{c}\text { Brezilya'nın } \\
\text { Eczacllk } \\
\text { Ürünleri } \\
\text { İhracat }\end{array}$ & $\begin{array}{c}\text { Brezilya'nın } \\
\text { Toplam Mal } \\
\text { İhracatı }\end{array}$ & $\begin{array}{c}\text { Dünya'nın } \\
\text { Eczacılık } \\
\text { Ürünleri } \\
\text { İhracatı }\end{array}$ & $\begin{array}{c}\text { Dünya'nın } \\
\text { Toplam Mal } \\
\text { İhracatı }\end{array}$ \\
\hline 2008 & 421,134 & $132.027,196$ & 961,456 & $197.942,443$ & $398.952,804$ & $15.978,251,440$ \\
\hline 2009 & 429,061 & $102.142,613$ & $1.078,560$ & $152.994,743$ & $420.144,792$ & $12.348,636,406$ \\
\hline 2010 & 558,172 & $113.883,219$ & $1.276,190$ & $201.915,103$ & $443.254,180$ & $15.094,313,523$ \\
\hline 2011 & 566,797 & $134.906,869$ & $1.453,345$ & $256.038,702$ & $459.199,227$ & $18.008,382,191$ \\
\hline 2012 & 661,783 & $152.461,737$ & $1.494,772$ & $242.578,014$ & $469.486,097$ & $18.338,298,382$ \\
\hline 2013 & 754,085 & $151.802,637$ & $1.516,023$ & $242.032,979$ & $488.177,715$ & $18.869,747,611$ \\
\hline 2014 & 805,583 & $157.610,158$ & $1.569,853$ & $225.098,405$ & $512.500,356$ & $18.866,492,119$ \\
\hline 2015 & 878,149 & $143.850,376$ & $1.330,856$ & $191.126,886$ & $495.858,412$ & $16.224,464,135$ \\
\hline 2016 & 826,774 & $142.529,584$ & $1.201,293$ & $185.235,399$ & $493.872,129$ & $15.878,996,086$ \\
\hline 2017 & 875,310 & $156.992,940$ & $1.247,333$ & $217.739,177$ & $527.490,876$ & $17.545,700,714$ \\
\hline
\end{tabular}

Kaynak: www.trademap.org

Bu çalışmada 2008-2017 yılları arasında eczacılık sektöründe Türkiye ve Brezilya'nın dış ticaret performanslar hesaplanacaktır. Rekabet gücünün hesaplanmasında kullanılacak olan endeksler ise 
açıklanmış karşılaştırmalı üstünlükler endeksi, nispi ihracat avantaj endeksi ve karşılaştırmalı ihracat performansı endeksidir.

\subsection{Açıklanmış Karşılaştırmalı Üstünlükler Endeksi}

Rekabet gücünü belirlemek ülkeler için oldukça önemlidir. Rekabet gücü bir ülkenin ticaretten sonra elde edilen verilerle birlikte karşılaştırmalı olarak gözlenebilmesidir. Rekabet gücünün ölçülmesinde en çok kullanılan yöntemlerden biri olan açıklanmış karşılaştırmalı üstünlükler endeksi (AKÜ), Balassa (1965) tarafından ortaya atılmıştır. AKÜ'de bir ülkenin sektör/endüstri veya ülkeler arasında karşılaştırmalı üstünlüğün var olup olmadığını hesaplamak istemiştir (Şahinli, 2011: 235). Balassa formülü şu şekilde açıklamıştır (Aydoğmuş, 2009: 10);

$$
A K \ddot{U}_{i j}=\left[\left(X_{i j} / X_{i t}\right) /\left(X_{w j} / X_{w t}\right)\right]
$$

$\dot{\mathrm{I}}=$ Ülke

$\mathrm{J}=$ Dış ticarete konusu olan mal

AKÜ $\ddot{\mathrm{ij}}_{\mathrm{ij}}=\dot{\mathrm{I}}$ ülkesinin j malındaki ihracat performansı

$\mathrm{X}_{\mathrm{ij}}=\dot{\mathrm{I}}$ ülkesinin $\mathrm{k}$ ülkesine $\mathrm{j}$ malı ihracatı

$\mathrm{X}_{\mathrm{it}}=\dot{\mathrm{I}}$ ülkesinin $\mathrm{k}$ ülkesine toplam ihracatı

$X_{w j}=$ Dünya'nın k ülkesine j malı ihracatı

$X_{w t}=$ Dünya'nın k ülkesine toplam ihracatı

Yıllara göre endeksleri hesaplanan ülkelerin AKÜ>1 olması ülkelerin üretilen malda karşılaştırmalı üstünlüğe sahip olduğunu gösterir. Yani dünya ihracatında ilgili malın Pazar payında rekabet ettiği sonucuna varılır. Eğer AKÜ $<1$ olması durumunda ise ülkede üretilen malda karşılaştırmalı üstünlüğe sahip olmadığı görülmektedir. AKÜ=1 olması durumda ise dünya ihracat payına eşit olduğunu ve uzmanlaşma seviyesine eşit olduğunu gösterir.

Ayrıntı bir analizde ise karşılaştırmalı üstünlüğün gücünü incelemek için Balassa'nın AKÜ katsayısını 4 kademede oluşturulabilir (Erkan, 2012: 199):

1. $0<\mathrm{AKÜ}<1 \Rightarrow$ Karşılaştırmalı üstünlük yoktur.

2. $1<\mathrm{AKÜ}<2 \Rightarrow$ Zayıf bir karşılaştırmalı üstünlük vardır.

3. $2<\mathrm{AKÜ}<3 \Rightarrow$ Orta derece bir karşılaştırmalı üstünlük vardır.

4. $3<\mathrm{AKÜ}<4 \Rightarrow$ Güçlü bir karşılaştırmalı üstünlük vardır.

\subsection{Nispi İhracat Avantajı Endeksi (NİA)}

Nispi ihracat avantaji endeksi belirlenen bir ürünün belirlenen ülkede dünya piyasalarında sahip olduğu ihracat payının diğer tüm mallarda dünya ihracatında sahip olduğu paya oranıdır. Endeks bu özelliğinden dolayı ele alınması ülkelerin ve malların dünyadaki toplam ihracat hesaplanırken dışta tutulmasına, bundan dolayı da ele alınan ülke ve malların iki defa hesaplanmaya dâhil edilmesinin önüne geçilmiş olur (Altay ve Gürpınar, 2008: 263). Formülü şu şekilde açıklanmıştır;

$$
\text { NíA } \mathbf{A}_{\mathrm{ij}}=\left[\left(\mathbf{X}_{\mathrm{ij}} / \sum_{\mathrm{I}, \mathrm{I} \neq \mathbf{j}} \mathbf{X}_{\mathrm{il}}\right) /\left(\sum_{\mathbf{k}, \mathbf{k} \neq \mathbf{i}} \mathbf{X}_{\mathbf{k j}}\right) /\left(\sum_{\mathbf{k}, \mathbf{k} \neq \mathbf{i}} \sum_{\mathrm{I}, \mathrm{I} \neq \mathbf{J}} \mathbf{X}_{\mathbf{k l}}\right)\right]
$$

X: İhracatı

İ: Endeksteki ürün kategorisi

K: Endeksteki ürün kategorisi

J: Seçilen ülke

I: Seçilen ülke 
Z. Turhan - S. C. Kayıkçığlu - A. E. Çağlar 11/4 (2019) 2680-2690

Hesaplan endeks değerleri NİA $>1$ olduğunda ürün ve kategoride ülkenin rekabet avantajının olduğunu gösterir. NİA<1 olduğunda ise ülkenin rekabet avantajının olmadığını göstermektedir (Gürpınar ve Barca, 2007: 44)

\subsection{Karşılaştırmalı İhracat Performansı Endeksi (KİP)}

Belirlenen ülkelerin ilgili pazarda karşılaştırmalı ihracat performanslarını belirlemek amacıyla Donges (1982) tarafından ortaya atılmıştır. KİP endeksi aşağıdaki gibi formüle edilmiştir (Atış, 2014: 320).

$$
\operatorname{KiP}_{i k j}=\left(X_{i j} / X_{k j}\right) /\left(X_{i t} / X_{k t}\right)
$$

$\mathrm{KIIP}_{\mathrm{ikj}}=\dot{\mathrm{I}}$ ülkesinin rakip ülke olan $\mathrm{k}$ ülkesi karşısında ilgili pazarda $\mathrm{j}$ malındaki karşılaştırmalı ihracat performansı katsayısını ifade eder.

$\mathrm{X}_{\mathrm{ij}=}=\dot{I}$ ülkesinin J malında ilgili pazara ihracatını

$\mathrm{X}_{\mathrm{kj}}=$ Rakip ülkelerin $\mathrm{j}$ malındaki pazar ihracatı

$\mathrm{X}_{\mathrm{it}}=\dot{I}$ ülkesinin ilgili pazara toplam ihracatı

$\mathrm{X}_{\mathrm{k}}=$ Rakip ülkelerin ilgili pazara toplam ihracatını

Hesaplanan KİP endeksine göre belirlenen bir ülkenin farklı mal grupları için hesaplanmış olan KİP değeri KİP $>1$ ise ülke o üründe ihracat avantajı olduğunu, KİP $<1$ ise ülkenin o üründe ihracatta dezavantaj1 olduğunu göstermektedir ( Kösekahyalığlı ve Özdamar, 2011: 34).

\section{AMPIRİK BULGULAR}

Bu çalışmada dünya eczacıllk sektöründe rekabet içinde olan Türkiye ve Brezilya arasındaki ihracat verileri kullanılarak karşılaştırmalı rekabet gücünü ve rekabet güçlerini belirlemeye istenmiştir. Elde edilen veriler doğrultusunda daha gerçekçi ve perspektif bir yaklaşım oluşturulmaya çalışılmıştır. Aşağıdaki tabloda Türkiye ve Brezilya'nın eczacılık sektöründe ticaret sonrası belirlenen yıllarda metodoloji ve veri setinde açiklanan endekslerle kullanılarak hesaplanmıştır.

Tablo 3. Türkiye ve Brezilyanın Eczacllık Sektöründe Belirlenen Rekabet Gücü Endekslerine Göre Hesaplanan Değerler

\begin{tabular}{|c|c|c|c|c|c|c|}
\hline \multirow{2}{*}{ YILLAR } & \multicolumn{3}{|c|}{ TÜRKIYE } & \multicolumn{3}{c|}{ BREZILYA } \\
\cline { 2 - 7 } & AKÜ & NIA & KIP & AKÜ & NIAA & KIPP \\
\hline $\mathbf{2 0 0 8}$ & 0,127751 & 0,124039 & 0,65669909 & 0,194535 & 0,188660 & 1,52276740 \\
\hline $\mathbf{2 0 0 9}$ & 0,123462 & 0,035487 & 0,59586010 & 0,207199 & 0,199534 & 1,67824640 \\
\hline $\mathbf{2 0 1 0}$ & 0,166905 & 0,161752 & 0,77546420 & 0,215232 & 0,207978 & 1,28955010 \\
\hline $\mathbf{2 0 1 1}$ & 0,164766 & 0,160210 & 0,74016810 & 0,222606 & 0,215704 & 1,35104440 \\
\hline $\mathbf{2 0 1 2}$ & 0,169547 & 0,164756 & 0,70441930 & 0,240691 & 0,233563 & 1,41960910 \\
\hline $\mathbf{2 0 1 3}$ & 0,192012 & 0,186730 & 0,79306680 & 0,242114 & 0,234980 & 1,26092790 \\
\hline $\mathbf{2 0 1 4}$ & 0,188158 & 0,182711 & 0,73891200 & 0,256734 & 0,249236 & 1,36445897 \\
\hline $\mathbf{2 0 1 5}$ & 0,199742 & 0,193409 & 0,87669380 & 0,227836 & 0,220348 & 1,14064913 \\
\hline $\mathbf{2 0 1 6}$ & 0,186505 & 0,180396 & 0,89445160 & 0,208513 & 0,201420 & 1,11800351 \\
\hline $\mathbf{2 0 1 7}$ & 0,185455 & 0,179535 & 0,97327580 & 0,190347 & 0,183967 & 1,02745798 \\
\hline
\end{tabular}




\section{Z. Turhan - S. C. Kayıkçıŏlu - A. E. Çağlar 11/4 (2019) 2680-2690}

Tablo 3'deki değerler ayrı ayrı incelendiğinde açıklanmış karşılaştırmalı üstünlükler endeksi (AKÜ) iki ülke içinde değer olarak 1'den küçük olduğu görülmektedir. Türkiye ve Brezilya'nın eczacılık sektöründe üretilen ürünlerde karşılaştırmalı üstünlüğünde dezavantajlı olduğu söylenebilir. Bunun temel nedeni ise sektörde de ülke içinde uzmanlaşmanın sağlanamamış olmasından kaynaklanmaktadır. 2009-2010 yılları arasında iki ülkede bir artış kaydetseler de karşılaştırmalı üstünlüklerindeki dezavantajlı durumdan kurtulamamışlardır. Türkiye'nin belirli bir trendi yakalayamadığı görülmektedir. Türkiye'nin 2013 ve 2015 yılları arasında en yüksek değerleri aldığı daha sonra sektörde bu değerleri koruyamadığı gözlenmektedir. Brezilya ise 2008-2014 yılları arasında sektördeki trendini artmış olduğu görülse de 2014-2017 yıllarında bu trend artışı azalmaya başlamıştır. İki ülkenin karşılaştırmalı üstünlüğü kıyaslandığında Brezilyanın 20082013 yıllarında Türkiye ye nispeten üstün olduğunu 2013-2017 yıllarındaki değerlerinin birbirine daha yakın olduğu görülmektedir. Bundan dolayı Brezilya, Türkiye ye göre eczacılık sektöründe karşılaştırmalı üstünlükte daha az dezavantajlı olduğu görülmektedir.

Nispi ihracat avantajı endeksi (NİA) verilerine göre, iki ülkenin durumları yine benzerlik göstermektedir. İki ülkenin de nispi ihracat değerleri 1'den küçük olduğu için rekabet avantajlarının dezavantajlı olduğu görülmektedir. Rekabet gücünün düşük olmasının temel taşı olan uzmanlaşma bu endekste de eksikliğini göstermektedir. Dünya pazarındaki payları küçük olan iki ülkenin değer oranlarında Brezilya'nın Türkiye ye oranla önde olduğu görülmektedir. 2008-2014 yıllarında artan trende sahip olan Brezilya 2014 yllında AKÜ' de olduğu gibi değeri diğer yıllara kıyasla daha yüksektir. Daha sonra ki yıllarda artış gösteren bu ihracat avantajı düşüşe başlamıştır ve nispi ihracat avantajı endeksini avantaja çevirememiştir. Türkiye açısından incelendiğinde ise, 2008-2010 yıllarında belirli bir trend yakalanamadığı 2011-2015 yıllarında trendinin artığını 2016-2017 yıllarında ise düşüşe geçtiği gözlemlenmiştir. İki ülkenin de eczacılık sektöründeki pazar payları küçük olsa da Brezilya'nın nispi ihracat avantajı olarak Türkiye'nin önünde olduğu ve pazar payının kısmen daha fazla olduğu görülmektedir.

Karşılaştırmalı ihracat performansı endeksinde (KİP), Türkiye'nin değerlerinin 1'den küçük olduğu görülmektedir. Bu yüzden dolayı Türkiye'nin eczacılık sektöründeki ihracat performansında dezavantaja sahiptir. Brezilya ise karşılaştırmalı ihracat performansı değerlerinde 1'den büyük olduğu için eczacılık sektöründe ihracat performansı avantajlı durumdadır. Fakat iki ülkenin de değerlerinde dalgalanmaların yaşandığı görülmektedir. Bu dalgalanmaların en çok brezilyada olduğu ve 2009 yılından 2017 yıllına kadar ihracat performansında büyük ölçekli düşüşün olduğu görülmektedir. Bu düşün nedeni olarak yeterince kaynak bulunamaması, Ar-Ge faaliyetlerinin azalması ve ülke içinde yaşanan ekonomik, sosyal sorunlar gösterilebilir. Türkiye açısında incelendiğinde ise dezavantajlı bir duruma sahip olsa da sektörde özellikle de 2014-2017 yıllarında bir yükselişin olduğu görülmektedir. Fakat bu artışı belirlenen yıllar içinde avantaja çevirememiştir. 2017 yıllarındaki KİP oranları birbirine yakın olan iki ülke için Türkiye karşılaştırmalı ihracat performansında Brezilya ya göre geri durumda olsa da kendini geliştirmekte olan bir sektör durumundadir.

İncelenen bu üç endeksler de varılan sonuçlara göre Brezilya'nın Türkiye ye göre rekabet gücünün daha yüksek olduğu sonucu çıkarılmıştır. Elde edilen sonuçlara bakılarak iki ülke arasındaki değer farkının çok olmadığı görülmektedir. Pazar payları küçük olan iki ülkenin de aralarındaki tek fark olarak Türkiye'nin son yıllarda sektörde kendini rekabet gücünü artırdığını Brezilya'nın ise rekabet gücünde özellikle de ihracat performansında düşüş yaşadığı görülmektedir.

\section{SONUÇ VE ÖNERİLER}

Küreselleşen dünyada rekabet gücünün ülkeler için önemi gün geçtikçe artığı görülmektedir. Günümüzde rekabetin ülke bazında sağlanasında işletmelerin ve firmaların kaynakları etkili ve verimli kullanarak üretim yapmasından geçmektedir. Üretimin ise iç piyasayı karşılayıp, üretilen ürünlerin veya üretim fazlası ürünlerin ihracatı ile rekabet gücü elde edilir. Rekabet gücü artan ülkelerde pazar payı artar ve pazar da yer alan diğer rakipleriyle rekabet eder.

Yapılan çalışmamızda ise Türkiye ve Brezilya'nın eczacılık sektöründe belirlenen endekslerle rekabet edilebilirliği karşılaştırılmış ve iki ülkenin de rekabet gücünün yüksek olmadığı sonucu çıkarılmıştır. Elde edilen sonuçlarla iki ülke kıyaslandığında ise Brezilya'nın Türkiye ye karşı rekabette üstünlügünün olduğu sonucuna varılmıştır. Bunun en önemli nedeni ise Brezilya'nın devlet desteğinin oldukça fazla olması ve Amerika Birleşik Devletleri ve Çin gibi pazar payı yüksek olan devletlere yakın olmasının etkisi büyüktür. 


\section{Z. Turhan - S. C. Kayıkçığlu - A. E. Çağlar 11/4 (2019) 2680-2690}

Latin Amerika'nın en büyük devleti olan ve dünya ekonomisinde 9. sırada yer alan Brezilya daha çok jenerik yani kopya ilaç üretimi yaparak Afrika ülkelerinin ilaç pazarında önemli bir yer aldığ Ayrıca Brezilya'nın ilaç üretiminde teknolojik alt yapısı oldukça yüksektir. Bunun nedeni ise devletin sektöre yatırım yapmasından kaynaklanmaktadır. Lakin Brezilya'nın son yıllarda sektörde büyük düşüşler yaşmaktadır. Bu düşüşlerin altında uzmanlaşma da eğitimin eksik kalması ve gelir adaletsizliğinin yaratmış olduğu ekonomik daralmanın etkisiyle son yıllarda Brezilya'nın eczacılık sektöründe düşüşe geçmesine neden olmuştur.

Türkiye eczacılık sektörü incelendiğinde rekabet gücü Brezilya ya kıyasla düşüktür. Türkiye'de eczacılık sektörünün Brezilya da olduğu gibi tam anlamıyla devlet desteği yoktur. Özelleştirme ile birlikte ÇUF'ların var olduğu piyasada daha çok tedavide $\backslash$ korumada kullanılmak üzere ilaç üretimi yapılmakta ve ihraç edilmektedir. İlaç üretiminde üretimi maliyetli ürünlerin üretimini yapmayan firmalar ithalat yolunu seçmektedirler. Fakat son yıllardaki yapılan teknolojik alt yapı çalışmaları, artan Ar-Ge faaliyetleri, sağlık kurumlarının artması ve eğitimli uzmanlaşmanın artmasıyla pozitif artışların olduğu da görülmektedir. Özellikle de Brezilya'ya kıyasla ihracat Pazar payını da artışlar olan Türkiye, sektörde rekabet gücünü artırması beklenmektedir.

Sonuç olarak iki ülkenin de eczacılık sektöründe rekabet gücü oldukça düşüktür. İki ülke birbiriyle kıyaslandığında Brezilyanın nispeten Türkiye ye karşı rekabet gücünde avantajlı olduğu görülmektedir. Türkiye eczacılık sektöründe maliyeti yüksek ilaçları ithal etmeyi bırakmalı katma değer yükünden kurtulmalıdır. Bunun yapılabilmesi içinde yerli firmaların bir politika oluşturması gerekmektedir. Ayrıca Türkiye kaynakların daha verimli kullanılarak üretimin artırılması ve konumum avantajının kullanılması sağlanmalıdır. Brezil ya için ise sektörde eğitimli uzmanlaşmalara önem verilmeli ve gelir dağılımını adaletsizliği azaltılarak iş gücü veriminin artırması sağlanmalıdır.

\section{KAYNAKLAR}

Altay, B., \& Gürpınar, K. (2008). Açıklanmış Karşılaştırmalı Üstünlükler ve Bazı Rekabet Gücü Endeksleri: Türk Mobilya Sektörü Üzerine Bir Uygulama. Afyon Kocatepe Üniversitesi İktisadi ve İdari Bilimler Fakültesi Dergisi, 10(1), 257-274.

Atış, A.G. (2014). Türkiye'nin Tekstil ve Konfeksiyon Sektörünün Karşılaştırmalı Rekabet Analizi /A Comparative Competition Analysis of Turkey's Textile and Clothing Sector. Ege Akademik Bakış, 14(2), 315-334.

Aydoğuş, İ., \& Diler, H. G. (2009). Tekstil Ürünleri İhracatında Stratejik Dış Ticaret Yaklaşımı: Türkiye ve Çin Üzerine Bir Uygulama. Afyon Kocatepe Üniversitesi İktisadi ve İdari Bilimler Fakültesi Dergisi, 11(2), $1-17$.

Çivi, E., Erol, İ., İnanlı, T., \& Erol, E. D. (2008). Uluslararası rekabet gücüne farklı bakışlar. Ekonomik ve Sosyal Araştırmalar Dergisi, Cilt: 4, Yı1:4, Sayı:1, ss. 1-22.

Erkan, B. (2012). Ülkelerin Karşılaştırmalı İhracat Performanslarının Açıklanmış Karşılaştırmalı Üstünlük Katsayılarıyla Belirlenmesi: Türkiye-Suriye Örneği. Uluslararası Yönetim İktisat ve İşletme Dergisi, 8(15), 195-218.

Gökmenoğlu, S. M., Akal, M., \& Altunışık, R. (2012). Ulusal Rekabet Gücünü Belirleyen Faktörler Üzerine Değerlendirmeler. Competition Journal / Rekabet Dergisi, 13(4), ss. 3-43.

Gürpınar, K., \& Barca, M. (2007). Türk Mobilya Sektörünün Uluslararası Rekabet Gücü Düzeyi ve Nedenleri. Eskişehir Osmangazi Üniversitesi İ̈BF Dergisi, 2(2), 41-61.

İEIS (2017) Türkiye İlaç Sektörü Raporu, Çevrimiçi, http://ieis.org.tr/ieis/tr/sektorraporu2017 , Erişim Tarihi: 01.01.2019.

Kaynak, S. (2016). Türk İlaç Sektörünün Rekabet Yapısı ve Yoğunlaşma Analizi. Çankırı Karatekin Üniversitesi İ̈F Dergisi, 6(2), 49-66.

Koç, M. \& Ozbozkurt, O., B., (2014). Ulusların Rekabet Üstünlüğü ve Elmas Modeli Üzerine Bir Değerlendirme. İşletme ve İktisat Çalışmaları Dergisi, 2(3), 85-91. 
Z. Turhan - S. C. Kayıkçığlu - A. E. Çağlar 11/4 (2019) 2680-2690

Kösekahyaoğlu, L. \& Özdamar, G., (2011). Türkiye, Çin ve Hindistan'ın Sektörel Rekabet Gücü Üzerine Karşılaştırmalı Bir İnceleme, Uludă̆ Üniversitesi, İktisadi ve İdari Bilimler Fakültesi Dergisi, Cilt/vol. XXX, Sayı/No 2, 29-49.

Kumral, N., (2008). "Bölgesel Rekabet Gücünü Artırmaya Yönelik Politikalar", Ege University, Working Papers in Economics.

Şahinli, M.A. (2008). Açıklanmış Karşılaştırmalı Üstünlükler Endeksi: Türkiye Pamuk Endüstrisi Üzerine Bir Uygulama. Sosyal Ekonomik Araştırmalar Dergisi, 11(21), 227-240.

Timuçin, D., (2010). "Türkiye'de Kobilerin Rekabet Gücü ve Rekabet Üstünlüğ̈̈ Sağlamada Kümelenmenin Etkisi", İstanbul Üniversitesi, Sosyal Bilimler Enstitüsü, İktisat Anabilim Dalı, Doktora Tezi.

TOBB (2012), İlaç Sanayi Meclisi Sektörü Raporu, 2011, Yayın Sıra No:2012/170, Türkiye.

Yaşgül, Y.S. (2013). "Yeni Kalkınmacı Devlet Modeli Bağlamında Ulusal İlaç Politikası: Brezilya Deneyimi", Marmara Üniversitesi İ̈BF Dergisi, Y1l: 2013, Cilt: XXXV, Sayı 11, 123-152. 